Table 2. McNemars test comparing PASP estimated by repeat TTE to hemodynamic parameters measured by repeat $\mathrm{RHC}$ when PVR is also considered

\begin{tabular}{lcc}
\hline Repeat TTE & \multicolumn{2}{c}{ Repeat RHC } \\
\cline { 2 - 3 } & $\begin{array}{c}\text { Stable or improved PASP } \\
\text { and PVR }\end{array}$ & $\begin{array}{c}\text { Deteriorated PASP or PVR }(>15 \%) \\
\text { or PVR }(>15 \%)\end{array}$ \\
\hline Stable or improved PASP & 24 & 10 \\
Deteriorated PASP $(>15 \%)$ & 5 & 11 \\
\hline
\end{tabular}

$\mathrm{P}=\mathrm{NS}$ (0.3).

can be safely monitored in the long-term by TTE. Further studies to help identify those patients at need for follow-up RHC are warranted.

Disclosure of Interest: None declared

DOI: 10.1136/annrheumdis-2017-eular.2204

\section{FRI0415 CAPILLAROSCOPIC ABNORMALITIES CORRELATE WITH ORGAN DAMAGE IN CHINESE PATIENTS WITH SYSTEMIC SCLEROSIS}

W.Y. Yeung ${ }^{1}$, C.C. Mok ${ }^{2}$, K.L. Lee ${ }^{1} .{ }^{1}$ Department of Medicine, Pamela Youde Nethersole Eastern Hospital; ${ }^{2}$ Department of Medicine, Tuen Mun Hospital, Hong Kong,

Objectives: To study the nailfold capillaroscopic patterns and microangiopathy evolution score (MES) and correlate with the severity of organ damage in Chinese patients with systemic sclerosis (SSc)

Methods: Patients who fulfilled the 2013 ACR criteria for SSc were studied. A full physical examination was performed. Blood was taken for SSc autoantibodies, along with a full lung function test and echocardiogram. The extent of skin involvement was assessed by the modified Rodnan skin score (mRSS). Organ damage of SSc was assessed by the Medsger disease severity scale. A Nailfold capillaroscopic examination was performed by a trained nurse blinded to the medical history of the patients. The following parameters were obtained: (1) capillaroscopy patterns (early, active and late); (2) Degree of enlarged capillaries, giant capillaries, capillary haemorrhages, capillary density, disorganization of vascular array and capillary ramification assessed by a semi-quantitative method; and (3) MES score (sum of capillary density, disorganization of vascular array and capillary ramification). Correlation among the capillaroscopic patterns, individual capillaroscopic parameters and the MES with organ damage was performed by the Spearman's rank correlation test.

Results: A total of 138 Chinese patients were studied ( $91.3 \%$ women; age $56.36 \pm 11.81$ years). The median disease duration was $8.14 \pm 6.21$ years. 39 $(28.3 \%)$ patients had DcSSc and $99(71.7 \%)$ had LcSSc. Anti-centromere, anti-Scl 70 and anti-RNA polymerase III antibodies were present in $28.6 \%, 28.5 \%$ and $5.6 \%$ of the patients respectively. Organ damage was present in all patients, most common being skin $(84 \%)$, lung $(79 \%)$, peripheral vascular $(74 \%)$ and Gl tract (46\%). The median mRSS was 6 (IQR $2-12)$. A total of 27 patients $(19.7 \%)$ had early SSc pattern on capillaroscopy, $40(29.2 \%)$ had active pattern and $68(49.6 \%)$ had late pattern. The median MES score was 3.02 (IQR 1.76-5.25). Patients with late SSc pattern on capillaroscopy had significantly longer disease duration and were more likely to have organ damage in the general, peripheral vascular and lung domains compared to those not having late SSc patterns. The total MES score correlated significantly with organ damage scores in the muscle (Rho 0.188; $\mathrm{p}=0.029$ ), $\mathrm{Gl}$ tract (Rho 0.169; $\mathrm{p}=0.048$ ) and lung (Rho $0.265 ; \mathrm{p}=0.006$ ) domains. Regarding individual components of the MES score, capillary density correlated significantly with scores in the peripheral vascular (Rho 0.460; $<<0.001$ ), skin (Rho $0.343 ; p<0.001$ ), joint/tendon (Rho 0.220; $p=0.011$ ), muscle (Rho 0.295; $p=0.001$ ), Gl tract (Rho 0.188; $p=0.028$ ) and lung (Rho $0.238 ; p=0.015)$ damage domains. Enlarged capillaries correlated significantly with scores in the muscles (Rho $-0.205 ; p=0.017$ ) and lung (Rho -0.213; $p=0.029$ ) damage domains. Giant capillaries and microhaemorrhages correlated significantly with scores in the peripheral vascular (Rho 0.239; $\mathrm{p}=0.005$ and Rho $0.228 ; \mathrm{p}=0.007$ respectively) damage domains. Disorganization of capillary array correlated significantly with scores in the lung (Rho 0.253; $p=0.009$ ) damage domain. Capillary ramifications correlated significantly with the scores in the kidney (Rho $0.171 ; p=0.048$ ) damage domains. Conclusions: In Chinese patients with SSc, capillaroscopic patterns and components of the microangiopathy evolution score were associated with severity of organ damage.

Disclosure of Interest: None declared

DOI: 10.1136/annrheumdis-2017-eular.2020

\section{FRI0416 CHARACTERISTICS AND CAPILLAROSCOPIC FINDINGS OF SYSTEMIC SCLEROSIS PATIENTS WITH SEVERE PERIPHERAL VASCULAR INVOLVEMENT RECEIVING SPECIFIC VASODILATOR TREATMENT}

Y. Yalçınkaya, A.U. Ünal, Z. Ertürk, U. Gazel, S. Kaymaz, A. Aksoy,

P. Atagündüz, N. İnanç, H. Direskeneli. Department of Internal Medicine, Division of Rheumatology, Marmara University, School of Medicine, Istanbul, Turkey

Background: Severity of peripheral vascular involvement (PVI)is known as an important determinig cause of morbidity in sytemic sclerosis (SSc). Different vasodilating agents have been found to reduce severity and contribute to healing of digital ulcers (DU)in SSc.
Objectives: We aimed to evaluate the characteristics and capillaroscopic patterns of the patients with severe PVI under different vasodilator therapeutic regimens. Methods: The patients were grouped as "severe PVI" if score of $\mathrm{PVI}$ is $\geq 2$ (PVT=2, digital pitting scars; PVT=3, digital tip ulcerations and PVT=4, digital gangrene; Medsger) and "non-severe PVI" if score of $\mathrm{PVI}$ is $\leq 1$ ( $\mathrm{PVI}=0$, no Raynaud's; $P V I=1$, Raynaud's requiring vasodilators). We included patients with severe PVI who received cyclic iloprost and bosentan and/or sildenafil and compared to non-severe PVI. Nail fold video-capillaroscopy (NVC)was assessed qualitatively (Cutalo et al., early, active and late patterns).

Results: Severe PVI group more frequently had diffuse cutaneous form, contractures, lung disease, anti-Scl70 positivity and high acute phase response and exposed to immunosuppressives (table-1).

Table 1. Demographics and characteristics of SSc Patients

\begin{tabular}{lccc}
\hline & $\begin{array}{c}\text { Non-severe PVI } \\
\mathrm{n}=32\end{array}$ & $\begin{array}{c}\text { Severe PVI group } 2 \\
\mathrm{n}=22\end{array}$ & $\mathrm{p}$ \\
\hline Age (year)/female (\%) & $44 \pm 15 / 88 \%$ & $48 \pm 12 / 87 \%$ & $\mathrm{NS}$ \\
Duration of Raynaud's/nonRaynaud's (year) & $9 \pm 9 / 5 \pm 5$ & $12 \pm 10 / 9 \pm 9$ & $\mathrm{NS}$ \\
Diffuse Cutaneous involvement & $5(16 \%)$ & $10(45 \%)$ & $\mathrm{P}=0,039$ \\
Anti-Scl70 (+) & $7(22 \%)$ & $11(50 \%)$ & $\mathrm{P}=0,024$ \\
Interstitial lung disease & $7(22 \%)$ & $14(64 \%)$ & $\mathrm{P}=0,001$ \\
Flexion contractures & $3(9 \%)$ & $10(45 \%)$ & $\mathrm{P}=0,008$ \\
Echo PAP $>40$ mmHg & $2(6 \%)$ & $4(18 \%)$ & $\mathrm{NS}$ \\
High acute phase response & $12(38 \%)$ & $18(82 \%)$ & $\mathrm{P}=0,002$ \\
FVC $\leq 80 \% /$ & $3(9 \%)$ & $12(55 \%)$ & $\mathrm{P}<0,001$ \\
DLCO $\leq 80 \%$ & $10(31 \%)$ & $14(64 \%)$ & $\mathrm{P}=0,011$ \\
Immunosuppressives- CYC (pulse) & $5(16 \%)$ & $9(41 \%)$ & $\mathrm{P}=0,018$ \\
- Azathioprin & $8(25 \%)$ & $10(46 \%)$ & $\mathrm{P}=0,030$ \\
- Mycphenolate mofetil & $2(6 \%)$ & $10(46 \%)$ & $\mathrm{P}<0,001$ \\
- Rituksimab & $1(3 \%)$ & $6(27 \%)$ & $\mathrm{P}=0,027$ \\
- Steroids (PRD $<10$ mg/d) & $11(34 \%)$ & $17(77 \%)$ & $\mathrm{P}=0,001$ \\
\hline
\end{tabular}

NS $=$ not significant

Scores of telangiectasia, skin, activity and severity were lower in non-severe group. NVC late pattern was frequent and early pattern was rare in severe PVI groups. Forty-one\% (9/22) of patients received second oral agent for PVI. Monotherapy and combination groups had similar scores (table-2).

\begin{tabular}{|c|c|c|c|c|}
\hline & $\begin{array}{c}\text { non-severe } \\
\text { PVI } \\
\text { n=32 }\end{array}$ & $\begin{array}{c}\text { severe } \\
\text { PVI } \\
\mathrm{n}=22\end{array}$ & $\begin{array}{c}\text { Cyclic iloprost } \\
\text { bosentan } \\
n=10\end{array}$ & $\begin{array}{c}\begin{array}{c}\text { Cyclic iloprost } \\
\text { bosentan+sildenafi } \\
n=9\end{array} \\
\text { a }\end{array}$ \\
\hline NVC-normal & $3(9 \%)$ & 0 & 0 & 0 \\
\hline -early pattern & $12(38 \%)^{* *}$ & $2(9 \%)$ & $1(10 \%)$ & $1(11 \%)$ \\
\hline -active pattern & $10(31 \%)$ & $2(9 \%)$ & $2(20 \%)$ & $0(0 \%)$ \\
\hline -late pattern & $8(25 \%)$ & $18(82 \%)^{*}$ & $7(70 \%)$ & $8(89 \%)$ \\
\hline Telangiectasia score (Shah) & $3,7 \pm 2,5 * *$ & $6 \pm 3,7$ & $4,8 \pm 3,2$ & $7,1 \pm 4,2$ \\
\hline Modified Rodnan skin score & $5,8 \pm 5^{*}$ & $13,5 \pm 8,7$ & $13,6 \pm 9,3$ & $13,2 \pm 7,6$ \\
\hline Activity score (Valentini) & $0,9 \pm 0,9 *$ & $2,1=1,2$ & $2,2 \pm 1,3$ & $2,2 \pm 1,2$ \\
\hline Severity score (Medsger) & $3,5 \pm 1,7^{*}$ & $7,5 \pm 2,4$ & $7,8 \pm 2,3$ & $7,4 \pm 2,7$ \\
\hline
\end{tabular}

Conclusions: NVC late pattern was frequent in severe PVI group with long disease duration, exposed to intensive immunosuppresives and received specific vasodilators for PVI. Disease activity and severity were higher in severe PVI group. One third of the severe group required oral combination therapy for PVI. Monotherapy and combination groups were similar in terms of severity. NVC is a useful method to monitor digital ischemia and severe organ involvement in SSc.

Disclosure of Interest: None declared

DOI: 10.1136/annrheumdis-2017-eular.3584

\section{FRI0417 EXERCISE-INDUCED PULMONARY HYPERTENSION IN SYSTEMIC SCLEROSIS PATIENTS: TRANSCRIPTOME ANALYSIS OF PERIPHERAL BLOOD AT THE EARLY STAGE OF THE DISEASE}

Y. Koyama ${ }^{1}$, S. Fuke ${ }^{2}$, Y. Sato ${ }^{3}$, T. Higuchi ${ }^{1} .{ }^{1}$ Center for Autoimmune Diseases, Division of Rheumatology; ${ }^{2}$ Division of Cardiology, Japanese Red Cross Okayama Hospital, Okayama; ${ }^{3}$ DNA Chip Research Inc., Tokyo, Japan

Background: Pulmonary arterial hypertension $(\mathrm{PAH})$ is prominent as a vascular involvement in systemic sclerosis (SSc), which remains a leading cause of death in spite of current best treatments. As the pulmonary vascular disease (PVD) can be well compensated for, more than a half of the pulmonary circulation is impaired before early $\mathrm{PAH}$ is detected. Although recent studies focused on molecular basis of the PVD, the underlying mechanisms have not been fully elucidated, especially at the early stage of the disease.

Objectives: To detect the subclinical PVD, and to explore the changes in transcriptome of peripheral blood at the early stage of SSc associated PAH. Methods: Total of 74 cases without PAH symptoms (NYHA I) with either Raynaud phenomenon (RP: $n=61$ ), skin sclerosis $(n=43)$ or SSc-related autoantibody (anti-RNP: $n=10$, centromere: $n=36$, topoisomerase-1: $n=2$, RNA polymerase III: $\mathrm{n}=2$ ) were enrolled. To detect the latent $\mathrm{PAH}$, exercise Doppler echocardiography (DE) with Master's two-step stress was carried out. Systolic PAP (SPAP) was determined by maximum velocities of tricuspid regurgitation jets, and exercise induced pulmonary hypertension (exPH) group was segregated from normal response group (exN) with using the definition of a SPAP greater than $40 \mathrm{~mm}$ $\mathrm{Hg}$ during exercise, or a exercise increase in SPAP by greater than $20 \mathrm{~mm}$ 